\title{
Nine years' experience of physiological correction of tricuspid atresia: long-term results and current surgical approach
}

\author{
JAAP OTTENKAMP, JOHN ROHMER, JAN M QUAEGEBEUR, A GERARD BROM, FRANCIS FONTAN \\ From the Departments of Paediatric Cardiology and Thoracic Surgery, University Hospital, Leiden, The Netherlands
}

ABSTRACT Fontan's correction has been performed without early death in 24 consecutive patients with tricuspid atresia. Eighteen patients had ventriculoarterial concordance (group I) and six discordance (group II). Late death related to infections occurred in three patients. The follow-up time in group I (16 survivors) ranges from 1 year 10 months to 7 years 5 months (mean 3 years 8 months) and in group II (five survivors) from 2 years 1 month to 5 years 6 months (mean 3 years 6 months). Early postoperative cardiac catheterisation showed arterial pulsatile pressure recordings in the pulmonary artery only in two patients in group I, in whom a valved conduit was used to connect the right atrial appendage with the outlet chamber. Patients with a valved conduit connected with either the pulmonary artery (group II) or the outlet chamber (two patients of group I) showed better preservation of right atrial contractions angiocardiographically and scored better in exercise tests than did patients with a non-valved conduit (14 patients of group I). In the latter patients evidence of regurgitant bloodflow from the outlet chamber into the right atrium was found. Reoperation was necessary in two patients. The outlet chambers showed a substantial increase in diameter after operation. No disturbances of kidney or liver function were found up to seven years after operation. The clinical condition has improved considerably in all survivors. It is concluded that the use of a valved conduit is preferable for connecting the pulmonary artery directly in cases of tricuspid atresia with ventriculoarterial discordance or the outlet chamber when there is ventriculoarterial concordance.

Since the original description by Fontan and Baudet ${ }^{1}$ of an operative technique to achieve a physiological correction of tricuspid atresia modifications have been proposed, using the patient's own pulmonary valve ${ }^{2}$ or prosthetic devices containing porcine valves ${ }^{3-6}$ to direct the systemic venous blood from the right atrium to the pulmonary artery. In all these techniques the outlet chamber is bypassed in cases of tricuspid atresia with ventriculoarterial concordance and therefore excluded from the pulmonary circuit. In 1976 Gago et al ${ }^{\prime}$ reported a successful correction in a patient with tricuspid atresia and ventriculoarterial concordance based on connection of the right atrium to the outlet chamber using a woven Dacron external conduit containing a porcine aortic valve. Murray et $a^{8}$ in 1977 described a successful correction in tricuspid atresia with ventriculoarterial concordance incorporating the outlet chamber in the pulmonary circuit without using a bioprosthetic valve.

Address for reprint requests: Dr Jaap Ottenkamp, Department of Paediatric Cardiology, University Hospital, Rijnsburgerweg 10, 2333AA - Leiden, The Netherlands.
A similar technique, connecting the right atrial appendage with the outlet chamber via a non-valved woven Dacron conduit, has been used in our institution since 1974 in 15 patients and the purpose of this paper is to report the long-term results in these patients and three others who had the same basicanatomy but were treated in a different manner. We alsoinclude six other consecutive patients with tricuspid atresia, ventriculoarterial discordance, and restricted pulmonary blood flow operated on in the same period, who were treated with a valved conduit (aortic homograft) inserted between the right atrial appendage and the pulmonary artery.

\section{Methods}

THE PATIENTS

From January 1972 to March 198024 consecutive patients with tricuspid atresia ranging in age from 3 to 23 years (mean 9 years 11 months, lowest body weight $12 \cdot 7$ $\mathrm{kg}$ ) underwent a Fontan operation at University Hospital, Leiden. On the basis of the classification of Edwards and Burchell, ${ }^{9} 17$ patients had tricuspid atresia 
Table 1 Data on patients before operation

\begin{tabular}{|c|c|c|c|c|c|c|c|}
\hline $\begin{array}{l}\text { Patient } \\
\text { No }\end{array}$ & $\begin{array}{l}\text { Age } \\
(y \cdot m)\end{array}$ & Sex & $\begin{array}{l}\text { Type of } \\
\text { tricuspid } \\
\text { atresia* }\end{array}$ & $\begin{array}{l}\text { Previous procedures } \\
\text { (age }-y . m)\end{array}$ & $\begin{array}{l}\text { Haemoglobin } \\
(g / d l)\end{array}$ & $\begin{array}{l}\text { Haematocrit } \\
(\%)\end{array}$ & $\begin{array}{l}\text { Arterial oxygen } \\
\text { saturation } \\
(\%)\end{array}$ \\
\hline 1 & 22.2 & $\mathbf{M}$ & Ib & & 26 & 78 & 77 \\
\hline 2 & $6 \cdot 10$ & $\mathbf{M}$ & $\mathrm{Ib}$ & Glenn (1.7) & 23 & 68 & 71 \\
\hline 3 & 7.7 & M & $\mathrm{Ib}$ & & 21 & 57 & 78 \\
\hline 4 & 10.8 & M & $\mathrm{Ib}$ & & 18 & 54 & 84 \\
\hline 5 & 23.4 & M & IIb & & 23 & 65 & 87 \\
\hline 6 & 18 & $\mathrm{~F}$ & Ib & Glenn (2.9), Blalock (12.6) & 16 & 49 & 86 \\
\hline 7 & 15 & $\mathbf{M}$ & Ib & Glenn $(0.11)$, Blalock $(8.10)$ & 16 & 51 & 86 \\
\hline 8 & 8.1 & M & IIb & Rashkind $(0.7)$, Glenn $(0.8)$ & 19 & 57 & 86 \\
\hline 9 & 6.8 & $\mathrm{~F}$ & $\mathrm{Ib}$ & Waterston $\dagger(0.6)$ & 18 & 55 & 80 \\
\hline 10 & 5.7 & $\mathrm{~F}$ & Ic & Banding pulmonary artery $(0.3)$ & 22 & 66 & 66 \\
\hline 11 & 10.8 & M & $\mathrm{Ib}$ & $\begin{array}{l}\text { Rashkind }(0.6) \text {, Glenn and } \\
\text { Hanlon }(0.8)\end{array}$ & 23 & 67 & 81 \\
\hline 12 & 7.4 & $\mathbf{M}$ & Ib & & 21 & 59 & 79 \\
\hline 13 & 7.3 & M & IIb & & 14 & 41 & 85 \\
\hline 14 & 7.2 & M & IIb & & 16 & 50 & 85 \\
\hline 15 & $4 \cdot \overline{11}$ & $\mathrm{~F}$ & $\mathrm{Ib}$ & $\begin{array}{l}\text { Blalock (0.4), Blalock (1.2), } \\
\text { Modified Brock (3.3) }\end{array}$ & 17 & 61 & 76 \\
\hline 16 & 5.5 & $\mathrm{~F}$ & Ib & Blalock (2.6) & 20 & 62 & 77 \\
\hline 17 & 7.5 & $\mathrm{~F}$ & $\mathrm{Ib}$ & Waterston $†(0.4)$ & 17 & 53 & 79 \\
\hline 18 & $10 \cdot 11$ & $\mathrm{~F}$ & $\mathrm{Ib}$ & Glenn (3.4) & 19 & 54 & 78 \\
\hline 19 & 13.7 & $\mathrm{~F}$ & $\mathrm{Ib}$ & Glenn (1.8), Blalock (6.11) & 17 & 51 & 87 \\
\hline 20 & 13.7 & $\mathbf{M}$ & Ib & Glenn $(0.3)$, Waterston $\dagger(9.7)$ & 17 & 51 & 82 \\
\hline 21 & 10.7 & M & IIb & Rashkind $(1.0)$ & 21 & 61 & 89 \\
\hline 22 & 3.0 & M & $\mathrm{Ib}$ & Blalock $(0.10)$ & 21 & 73 & 71 \\
\hline 23 & 4.5 & M & $\mathrm{Ib}$ & Waterston $\dagger(0.1 / 2)$ & 17 & 50 & 84 \\
\hline 24 & 8.6 & M & IIc & Banding pulmonary artery (4.0) & 20 & 60 & 91 \\
\hline
\end{tabular}

*Types according to classification of Edwards and Burchell ${ }^{9}$ :

Ib - ventriculoarterial concordance and restricted pulmonary blood flow; Ic - ventriculoarterial concordance and unrestricted pulmonary blood flow; Ilb - ventriculoarterial discordance and restricted pulmonary blood flow; IIc - ventriculoarterial discordance and unrestricted pulmonary blood flow.

†Dacron tube ( $6 \mathrm{~mm}$ diameter) between ascending aorta and main pulmonary artery.

type Ib, one patient type Ic, five patients type IIb, and one patient type IIc (table 1). Table 1 also shows that 23 previous palliative surgical procedures had been performed in 16 of the 24 patients, while three had undergone a Rashkind atrioseptostomy as an initial procedure.

\section{OPERATIVE TECHNIQUE}

The original technique described by Fontan and Baudet $^{1}$ was used only in the first patient. An aortic homograft was inserted between the right atrial appendage and the pulmonary trunk as well as in the orifice of the inferior caval vein. At the same time a Glenn anastomosis was constructed.

In the other 17 patients with tricuspid atresia and ventriculoarterial concordance a conduit was inserted between the right atrial appendage and the outlet chamber, with no use of caval valves. In 15 patients a nonvalved woven Dacron conduit (diameter $18-22 \mathrm{~mm}$ ) was used; in the remaining two patients (Nos 17 and 23) a fresh antibiotic-preserved adult-sized aortic homograft was used to connect the right atrial appendage with the outlet chamber. The atrial septal defect was closed as well as the bulboventricular foramen. Infundibulectomy of the outlet chamber and commissurotomy of the pulmonary valve were performed if necessary.

In the six patients with tricuspid atresia and ventriculoarterial discordance continuity between the right atrial appendage and the pulmonary artery trunk was established with a fresh antibiotic-preserved adultsized aortic homograft. The atrial septal defect was closed as well as the pulmonary valve and the proximal pulmonary trunk after disconnection of the pulmonary artery. Pre-existing systemic-to-pulmonary-artery shunts were taken down, while previous Glenn shunts were left intact.

\section{Results}

No early deaths occurred. Patient 1 died five months after operation from infective endocarditis originating from an infected aortic homograft placed in the inferior caval vein. In patient 10 the postoperative course was complicated by a chylothorax necessitating continuous pleural drainage and parenteral feeding, and although her cardiac condition was good (as was proved by cardiac catheterisation) she died on the 31 st postoperative day from septicaemia, most probably caused by an infected venous cutdown and resulting in disseminated intravascular clotting. The third late death occurred in patient 24 , who was in excellent health on discharge from hospital 14 daysafter correction, but was readmitted four weeks later because of cough and fatigue. The chest radiograph suggested tuberculosis, but although adequate medication was started before the diagnosis was confirmed by culture the boy died four months after 
Table 2 Early postoperative haemodynamic data

\begin{tabular}{|c|c|c|c|c|c|c|c|c|c|c|c|c|c|}
\hline \multirow{2}{*}{$\begin{array}{l}\text { Patient } \\
\text { No }\end{array}$} & \multirow{2}{*}{$\begin{array}{l}\text { Type of } \\
\text { tricuspid } \\
\text { atresia* }\end{array}$} & \multicolumn{10}{|c|}{ Pressure - phasic/mean $(\mathrm{mm} \mathrm{Hg})$. } & \multicolumn{2}{|c|}{ Oxygen saturation (\%) } \\
\hline & & $I V C$ & & $S V C$ & & $R A$ & & Outlet & chan & $r P A$ & & $I V C$ & Systemic arteria \\
\hline $\begin{array}{r}2 \\
3 \\
4 \\
6 \\
7 \\
8 \\
9 \\
11 \\
12 \\
13 \\
14 \\
15 \\
16 \\
17 \\
18 \\
19 \\
20 \\
21 \\
22 \\
23\end{array}$ & $\begin{array}{l}\text { Ib } \\
\text { Ib } \\
\text { Ib } \\
\text { Ib } \\
\text { Ib } \\
\text { IIb } \\
\text { Ib } \\
\text { Ib } \\
\text { Ib } \\
\text { IIb } \\
\text { IIb } \\
\text { Ib } \\
\text { Ib } \\
\text { Ib } \\
\text { Ib } \\
\text { Ib } \\
\text { Ib } \\
\text { IIb } \\
\text { Ib } \\
\text { Ib }\end{array}$ & $\begin{array}{l}10 / 6 \\
11 / 1 \\
24 / 12 \\
17 / 7\end{array}$ & $\begin{array}{l}8 \\
6 \\
18 \\
11 \\
10 \\
9 \\
11\end{array}$ & $\begin{array}{l}16 / 6 \\
17 / 11 \\
16 / 5\end{array}$ & $\begin{array}{l}10 \\
10 \\
9 \\
11 \\
8\end{array}$ & $\begin{array}{l}13 / 5 \\
15 / 3 \\
13 / 1 \\
21 / 13 \\
27 / 12 \\
21 / 4 \\
20 / 7 \\
15 / 6 \\
14 / 4 \\
18 / 4 \\
16 / 4 \\
18 / 6 \\
18 / 4 \\
14 / 6 \\
16 / 2 \\
17 / 7 \\
17 / 5 \\
14 / 2 \\
20 / 9 \\
16 / 5\end{array}$ & $\begin{array}{l}9 \\
9 \\
6 \\
15 \\
19 \\
11 \\
11 \\
10 \\
9 \\
11 \\
9 \\
9 \\
11 \\
10 \\
11 \\
11 \\
10 \\
8 \\
14\end{array}$ & $\begin{array}{l}17 / 7 \\
22 / 4-1 \\
16 / 2 \\
17 / 4 \\
15 / 6 \\
17 / 9 \\
20 / 3\end{array}$ & $\begin{array}{l}10 \\
14 \\
11 \\
11 \\
9\end{array}$ & $\begin{array}{l}12 / 5 \\
12 / 6 \\
10 / 6 \\
20 / 11 \\
26 / 15 \\
14 / 6 \\
13 / 7 \\
15 / 6 \\
9 / 4 \\
16 / 10 \\
13 / 6 \\
15 / 11 \\
15 / 9 \\
20 / 12 \\
16 / 4 \\
15 / 9 \\
15 / 6 \\
12 / 4 \\
14 / 8 \\
16 / 8\end{array}$ & $\begin{array}{l}7 \\
9 \\
7 \\
15 \\
18 \\
10 \\
10 \\
10 \\
6 \\
11 \\
9 \\
10 \\
14 \\
9 \\
11 \\
9 \\
7\end{array}$ & $\begin{array}{l}61 \\
66 \\
74 \\
56 \\
46 \\
68 \\
73 \\
53 \\
60 \\
62 \\
70 \\
70 \\
69 \\
60 \\
65 \\
59 \\
62 \\
62 \\
76 \\
77\end{array}$ & $\begin{array}{l}87 \\
92 \\
92 \\
86 \\
90 \\
92 \\
90 \\
85 \\
85 \\
90 \\
93 \\
90 \\
89 \\
93 \\
91 \\
96 \\
94 \\
83 \\
92 \\
96\end{array}$ \\
\hline
\end{tabular}

IVC - inferior vena cava; PA - pulmonary artery; RA - right atrium; SVC - superior vena cava.

*See table 1 for definition of types.

Table 3 Means and standard deviations of $\frac{R A_{d}-R A_{s}}{R A_{d}} \times 100$ (from angiograms)

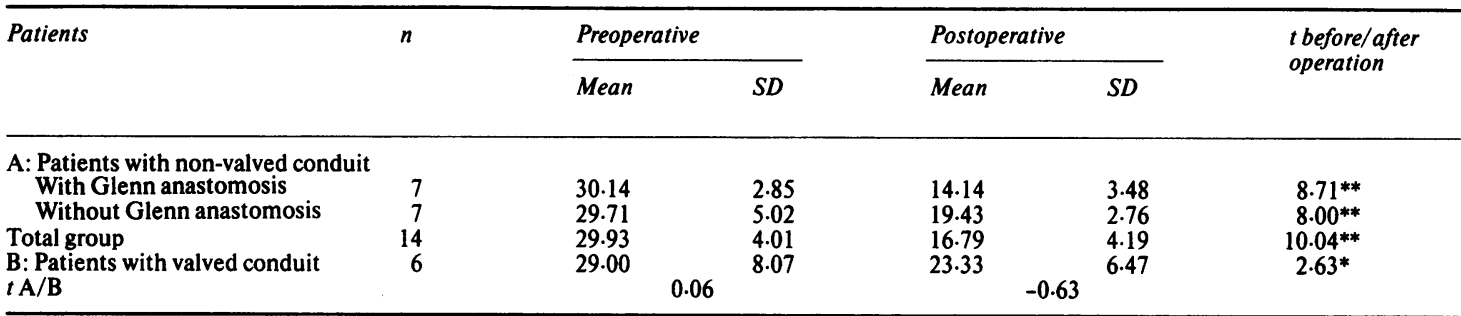

$\mathbf{R A _ { d }}$ - right atrial diastolic dimension; $\mathbf{R A}_{\mathrm{s}}$ - right atrial systolic dimension.

$*=p<0.05 ; * *=p<0.01$.

operation. Necropsy showed miliary tuberculosis, most probably originating from an infected aortic homograft. The 21 long-term survivors are well and have been followed for intervals ranging from 1 year 10 months to 7 years 5 months (mean 3 years 7 months).

FINDINGS OF EARLY POSTOPERATIVE CATHETERISATION Cardiac catheterisation has been performed about 14 days after operation in all survivors except patient 5 , who is well five years after correction. The results are shown in table 2. The mean right atrial pressure ranged from 6 to $19 \mathrm{~mm} \mathrm{Hg}$. The gradient in mean pressure caused by a non-valved conduit varied from 0 to $2 \mathrm{~mm} \mathrm{Hg}$. The maximal mean gradient found across an aortic homograft was $1 \mathrm{~mm} \mathrm{Hg}$. The pulmonary artery pressure recordings showed venous curves with prominenta-waves caused by right atrial contraction, not only in the patients with a direct anastomosis between the right atrial appendage and the pulmonary artery but also in those with a non-valved conduit between the right atrial appendage and the outlet chamber (figs 1 and 2). In contrast with these findings are the arterial pressure curves recorded in the pulmonary artery of the two patients (Nos 17 and 23) with an aortic homograft between the right atrial appendage and the outlet chamber(figs 3 and 4 ). Only in these two patients was there a positive contribution to pulmonary blood flow by contraction of the outlet chamber. By contrast, high v-waves with the same or almost the same pressures as the a-waves were found in the right atria of the 15 patients in whom a non-valved conduit was used to connect the right atrial appendage with the outlet chamber (fig 5). These prominent right atrial v-waves are compatible with and suggestive of retrograde blood flow from the outlet chamber into the right atrium during ventricular systole, as shown in patient 2 by angiocardiography six years after operation (fig 6).

PRESERVATION OF RIGHT ATRIAL FUNCTION

To estimate right atrial function, measurements were made of the shortening fraction (fig 7) on the preoperative and postoperative right atrial angiocardio- 


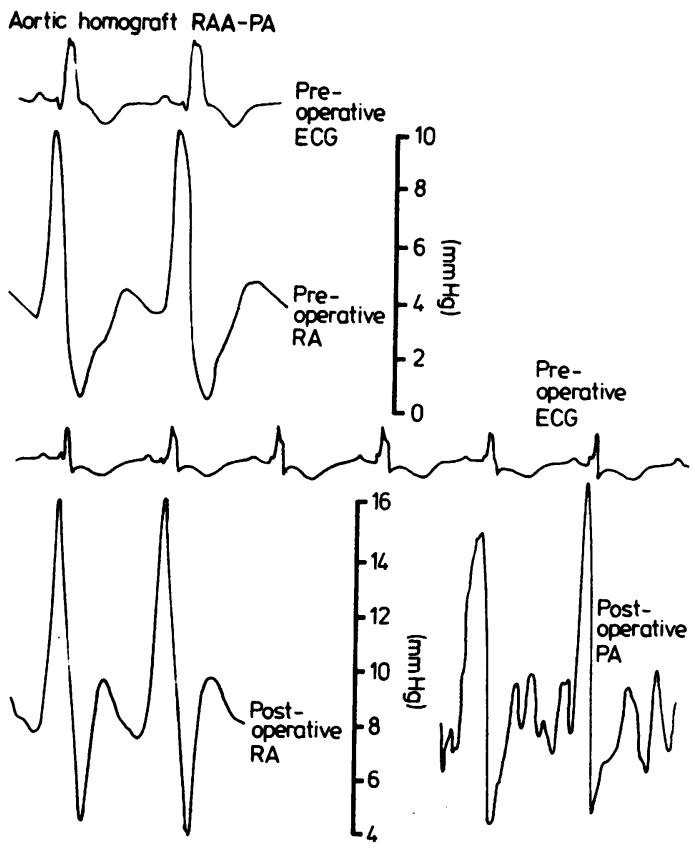

Fig 1 Preoperative and postoperative pressure recordings in a patient with tricuspid atresia and ventriculoarterial discordance who had an aortic homograft inserted between the right atrial appendage (RAA) and the pulmonary artery $(P A)$. The postoperative pulmonary artery pressure curve shows prominent a-waves ( $R A$ - right atrium).

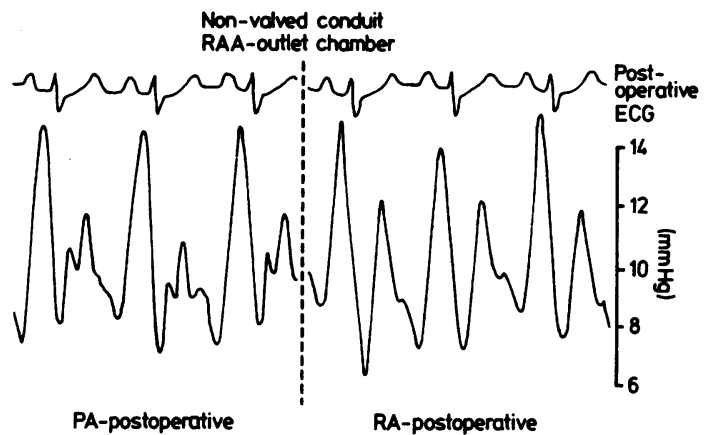

Fig 2 Postoperative pressure recordings in a patient with tricuspid atresia and ventriculoarterial concordance who had a non-valved conduit inserted between the right atrial appendage and the outlet chamber. The pulmonary artery pressure curve shows prominent a-waves.

gram. The difference in atrial diastolic and systolic dimension in the middle of both caval veins on the frontal right atrial angiocardiogram was divided by the right atrial diastolic dimension and multiplied by 100 to obtain the percentage of shortening. The mean shortening fractions before operation did not differ significantly, but after operation a clear difference emerged in favour

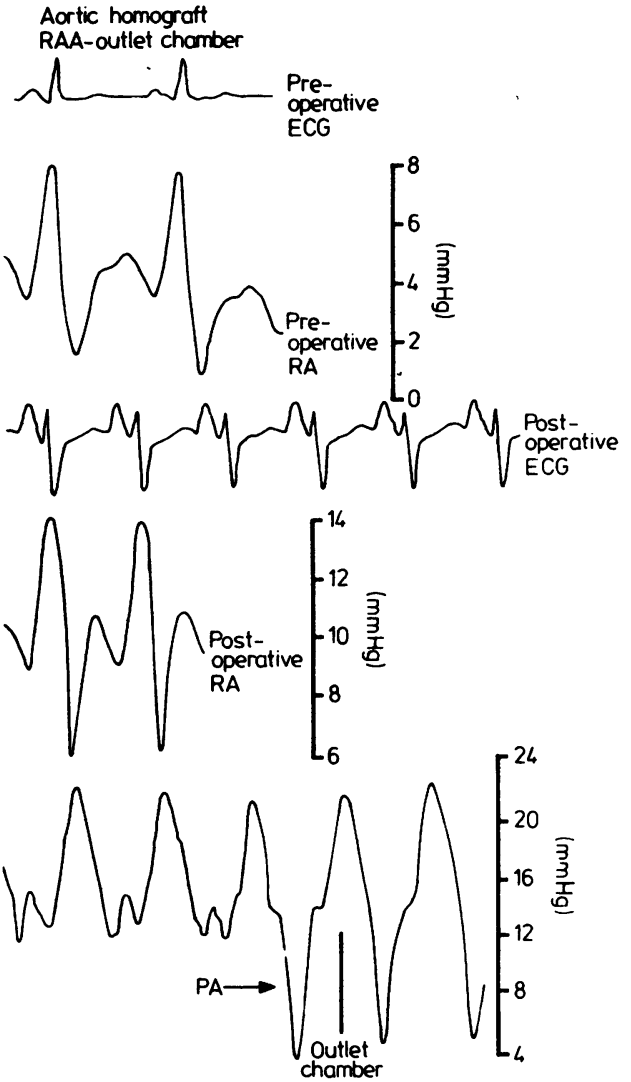

Fig 3 Preoperative and postoperative pressure recordings in patient 17: the withdrawal pressure curve from the pulmonary artery to the outlet chamber shows an arterial pressure curve in the pulmonary artery and a ventricularised pressure curve in the outlet chamber.

of the patients with a valved conduit between the right atrial appendage and the pulmonary circuit (table 3 ). A significant reduction in right atrial contraction was found in those patients in whom a non-valved conduit had been used. The reduction was even more obvious in patients with a Glenn anastomosis.

\section{ECHOCARDIOGRAPHIC STUDIES}

Serial echocardiograms have been performed in all patients, with particular attention to the development of the outlet chamber in those patients in whom it was incorporated into the pulmonary circuit. Preoperative and postoperative measurements of the outlet chamber could be made in nine patients. The anteroposterior diameter of the chamber was measured on M-mode echocardiograms, as shown in figure 8 , and compared with the end-diastolic dimension of the aortic root on the same echocardiogram. On M-mode echo the graft can be mistaken for the outlet chamber and therefore it is essential to visualise the endocardium of the free wall of the 


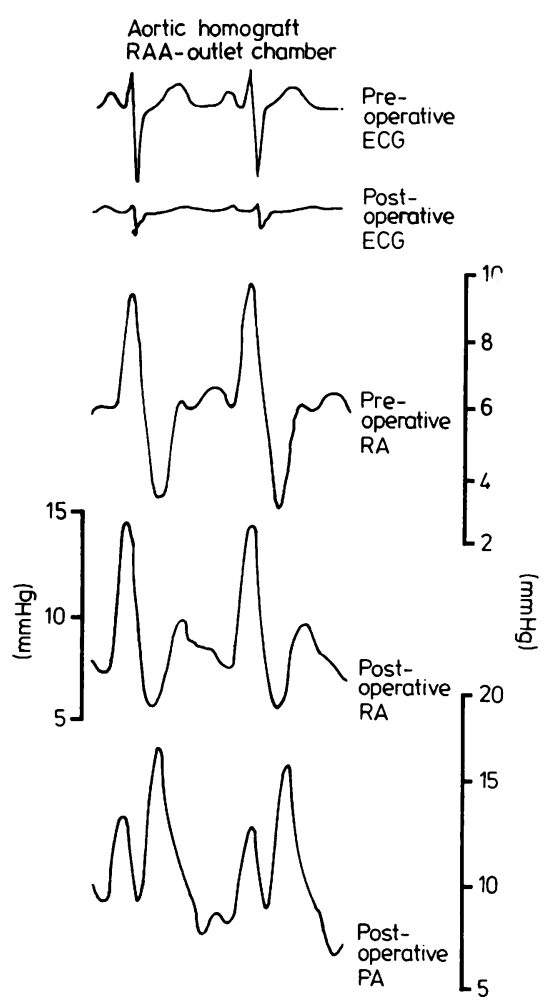

Fig 4 Preoperative and postoperative pressure recordings in patient 23: the postoperative pulmonary artery pressure curve shows prominent pressure waves caused by contraction of the outlet chamber.

outlet chamber and to realise that contractions often result in complete disappearance of the cavity of the outlet chamber in ventricular systole, owing to paradoxical motion of the "interventricular septum." In all cases in which good recordings were available a considerable increase in dimension of the outlet chamber was found after operation. The values for the nine patients in whom a comparison could be made between the preoperative and postoperative diameter of the outlet chamber are shown in figure 9. Before operation the outlet chamber diameter varied from $15 \%$ to $41 \%$ of the aortic root diameter, while after operation the values varied from $49 \%$ to $92 \%$. Shortly after surgical repair the outlet chamber had already increased substantially in diameter in many patients as a result of the infundibulectomy, but a further increase in diameter was seen in all patients studied.

\section{EXERCISE TOLERANCE}

Exercise tolerance was tested on a bicycle ergometer or treadmill in all survivors except patient 23 , who is in excellent health (NYHA Class I) 1 year 10 months after operation. As shown in figure 10, the results range from $47 \%$ to $113 \%$ of the values expected on the basis of sex,

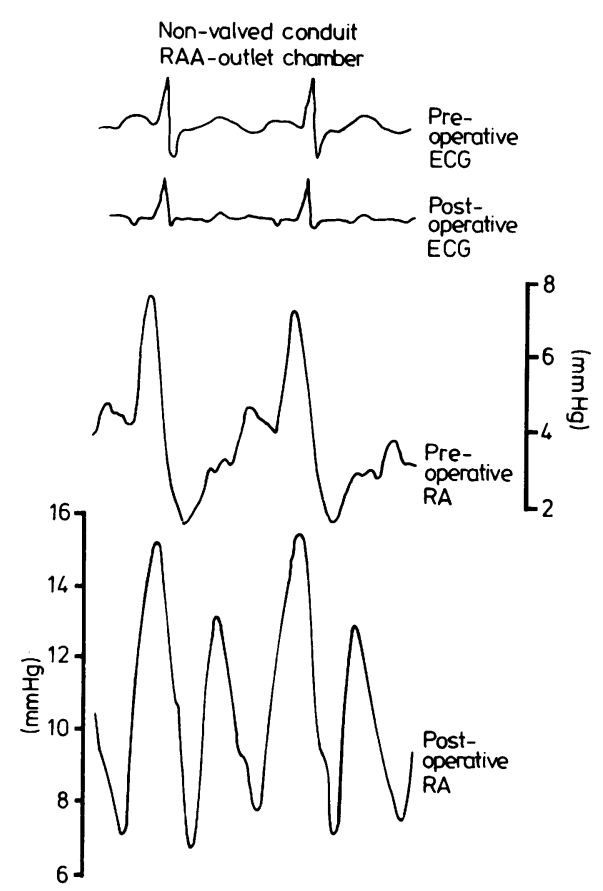

Fig 5 Preoperative and postoperative pressure recordings in a patient with tricuspid atresia and ventriculoarterial concordance who had a non-valved conduit inserted between the right atrial appendage and the outlet chamber; the postoperative pressure curve shows prominent $v$-waves almost as high as the a-waves.

weight, and height. The five patients with a valved conduit inserted between the right atrial appendage and the pulmonary artery scored best, with results ranging from $56 \%$ to $113 \%$ (mean $82 \%$ ). In the 15 cases of tricuspid atresia with ventriculoarterial concordance results ranged from $47 \%$ to $82 \%$ (mean $62 \%$ ), the best result being obtained in patient 17 , who (exceptionally in this group) had a valved conduit between the right atrial appendage and the outlet chamber. Patients with a non-valved conduit between the right atrial appendage and the outlet chamber and a Glenn anastomosis had low values, ranging from $47 \%$ to $71 \%$ (mean $56 \%$ ).

\section{SYSTEMIC ARTERIAL OXYGEN SATURATION}

Early after operation six of the 20 patients had a systemic arterial oxygen saturation below $90 \%$ (table 2), but more recently the saturation appeared to be at least $94 \%$ in all patients except three. Patient 12 has a value of $90 \%$ and is known to have a small residual right-to-left shunt at the atrial level, while in patient 2 cardiac catheterisation 6 years after correction showed no cardiac shunt despite a systemic arterial oxygen saturation of $86 \%$. In this boy evidence of right-to-left shunting in the right lung was found almost 12 years after construction of a Glenn anastomosis. In patient 21 a systemic arterial oxygen saturation of $84 \%$ was caused by a shunt from the 


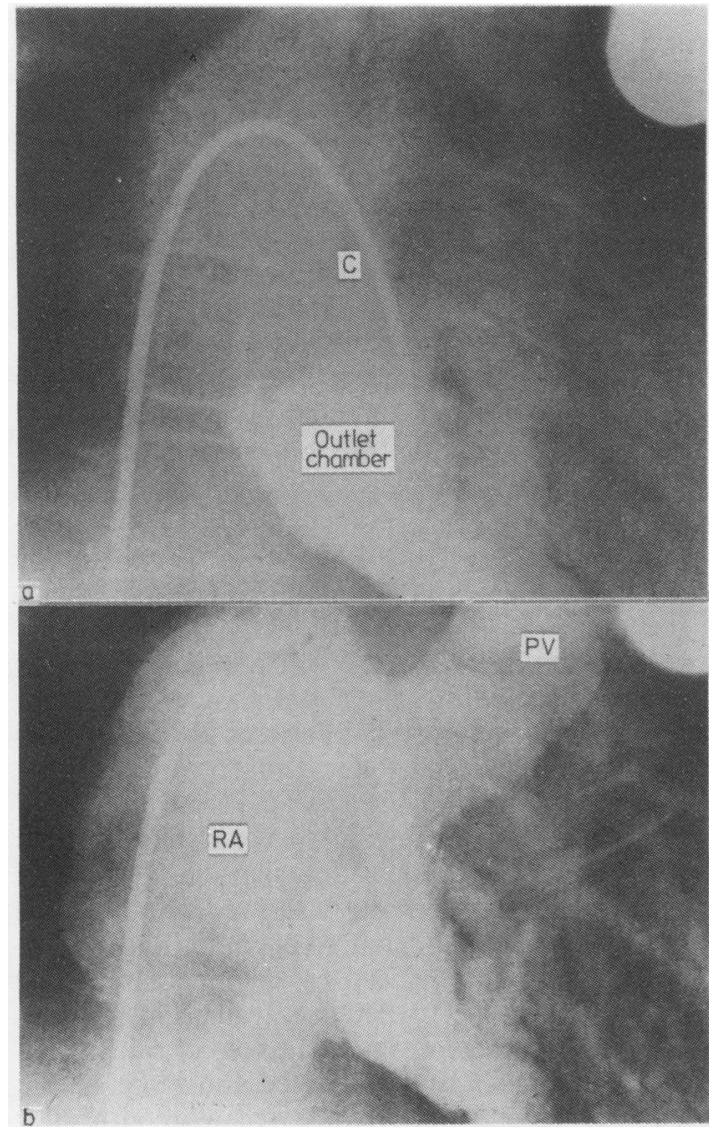

Fig 6 Angiocardiograms 6 years after the Fontan operation in patient 2: contrast medium is injected into the outlet chamber (above). In ventricular systole (below) the right atrium is filled by regurgitant flow from the outlet chamber (tricuspid insufficiency). C-Dacron conduit (non-valved); PV-patient's own pulmonary valve.

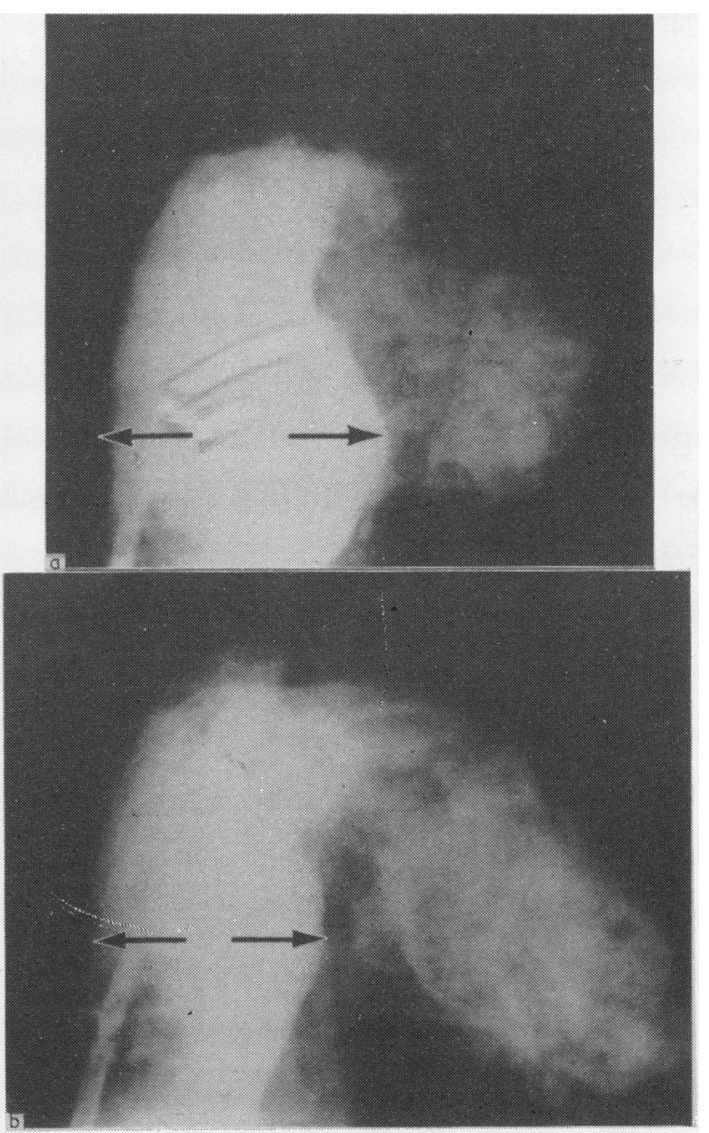

Fig 7 Right atrial shortening fraction measured angiographically: (a) right atrial diastolic dimension; (b) right atrial systolic dimension.

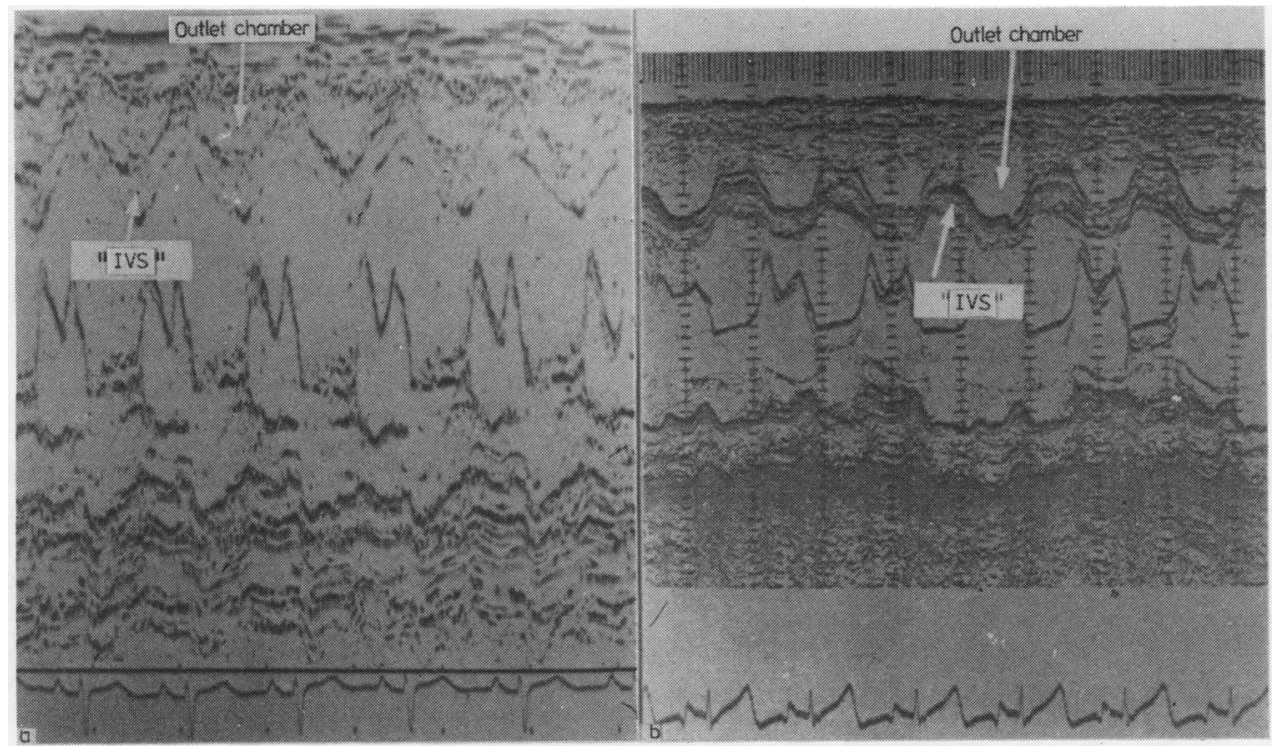

Fig 8 M-mode echocardiogram one month before (a) and 10 months after (b) the Fontan operation; an increase in dimension of the outlet chamber after operation is evident. IVS - interventricular septum. 


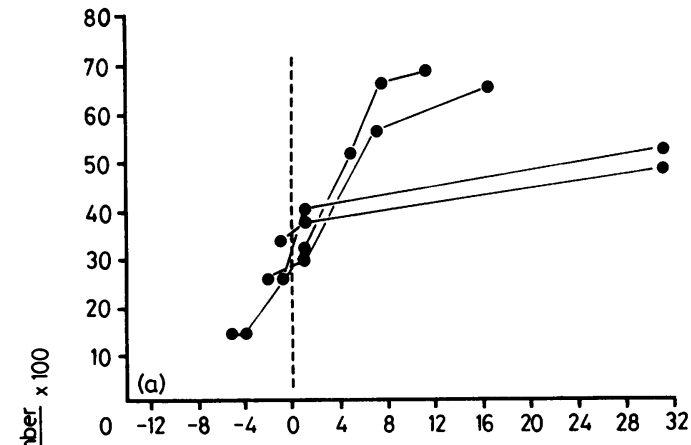

(a)

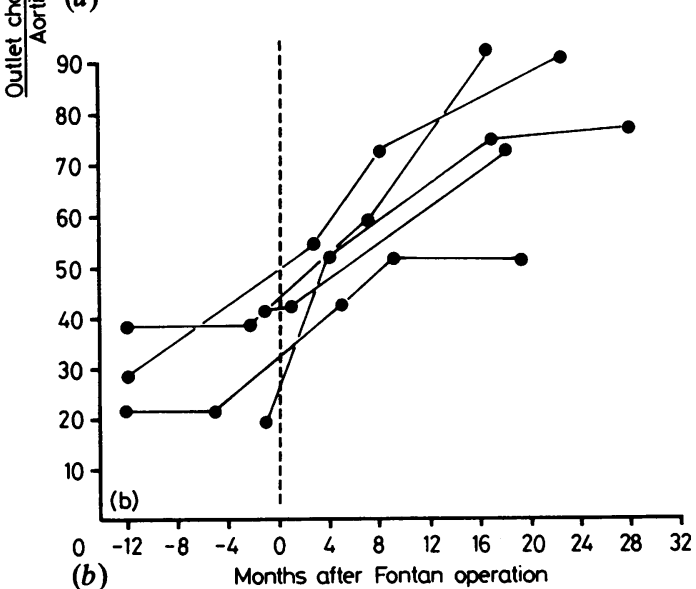

Fig 9 Growth of the outlet chamber related to aortic root dimension after the Fontan operation in nine patients with tricuspid atresia and ventriculoarterial concordance: data on four patients with a Glen anastomosis (a) and five patients without a Glenn anastomosis (b).

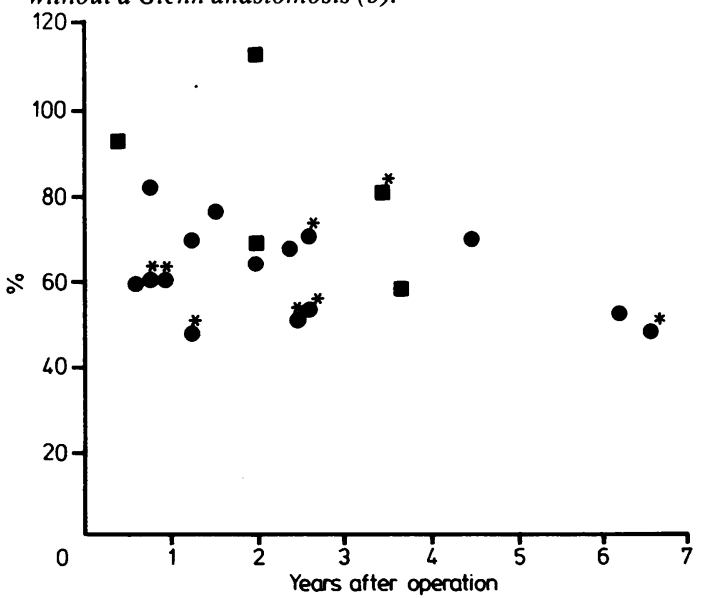

Fig 10 Results of exercise tests in 20 patients after the Fontan operation. $\bullet$ - tricuspid atresia with ventriculoarterial concordance; - tricuspid atresia with ventriculoarterial discordance; *- Glenn anastomosis. coronary sinus to the left atrium, which was subsequently closed.

\section{REOPERATIONS}

Patient 21 was operated on 14 months after the Fontan operation because of persistent cyanosis, despite his excellent clinical condition as reflected in the result of bicycle ergometry (93\% of expected exercise tolerance). Before operation a residual atrial septal defect was suspected, but a so-called unroofed coronary sinus was found and was evidently the cause of his right-to-left shunt. The communication between the coronary sinus and the left atrium was closed and after operation the systemic arterial oxygen saturation rose to $97 \%$. The boy is now pink and in excellent condition 10 months after reoperation.

Reoperation in patient 17 was required 2 years 5 months after an adult-sized aortic homograft $(22 \mathrm{~mm}$ diameter) had been inserted between the right atrial appendage and outlet chamber. The sternum could not be closed without removing a part of it. She progressed well until two years after operation, when she developed cyanosis on exertion, followed by signs of a low cardiac output. Cardiac catheterisation showed an obstructed and calcified aortic homograft. At operation the obstruction appeared to be caused by compression of the sternum, with local constriction and adjacent calcification. The aortic valve was not damaged or calcified. A new aortic homograft was inserted and more sternal tissue removed, and the girl is now well two months after replacement, although she needs diuretic treatment.

\section{PRESENT CLINICAL CONDITION}

Since operation the clinical condition of all 21 survivors has improved substantially. They are able to work or to attend school normally and to join in outdoor activities, including recreational sports. Apart from patient 17 (see previous paragraph), none of them requires digoxin or diuretic treatment. None of the patients show laboratory evidence of liver or kidney damage and the results of urine analysis are also normal. One patient (No 4) suffers from supraventricular tachycardias that did not respond to various antiarrhythmic drugs. He has now survived for more than six years since the operation without any treatment and the attacks of tachycardia are less frequent and do not interfere seriously with normal life.

\section{Discussion}

In the past decade since the original report of Fontan and Baudet ${ }^{1}$ many new techniques for the surgical treatment of tricuspid atresia have been advocated. Since 1974 we have treated 15 patients with tricuspid atresia who have had ventriculoarterial concordance using the surgical approach first described by Murray et al in $1977,{ }^{8}$ connecting the right atrial appendage with the 
outlet chamber via a non-valved woven Dacron conduit. Surprised by the remarkably uneventful postoperative course and excellent late results in patients suffering from tricuspid atresia with ventriculoarterial discordance in whom a valved conduit (aortic homograft) had been inserted between the right atrial appendage and the pulmonary artery, we decided to compare the preoperative and postoperative right atrial angiocardiograms of all patients. We found a much better preservation of right atrial contraction in the patients who had tricuspid atresia with ventriculoarterial discordance. As a result of these observations, together with the unmistakable signs of "tricuspid insufficiency" in the patients with tricuspid atresia and ventriculoarterial concordance in whom a non-valved conduit had been inserted, we changed our surgical approach. Since that time we have preferred to use a valved conduit also in tricuspid atresia with ventriculoarterial concordance, connecting the right atrial appendage with the outlet chamber as first described by Gago et al. ${ }^{7}$

The inclusion of a valve should help to reduce rightsided heart failure, especially in the early postoperative period, and this accords with the outcome in the two patients (17 and 23) in whom this technique was used. Ventricularised pressure tracings could be recorded in the outlet chambers of these patients and also normal atrial and pulmonary artery pressure curves, as previously reported by Bowman et al. ${ }^{10}$ Though we completely agree with their idea of producing a right ventricle with normal pulsatile haemodynamic characteristics, we believe that their technique of enlarging the outlet chamber with the distal end of the conduit is not necessary and might even be a limiting factor for effective functioning of the outlet chamber. The prevention of "tricuspid insufficiency" is also important in the long run as growth of the outlet chamber will occur and regurgitant flow might increase with time.

The disadvantages of using a porcine valve have been reported by many authors. ${ }^{5811-14}$ We have therefore used an adult-sized aortic homograft in nine patients with tricuspid atresia described in this paper, in four later patients with tricuspid atresia, and also in five patients with double-inlet ventricle undergoing a modified Fontan operation with closure of the tricuspid orifice. Unfortunately two patients died(Nos 1 and 24)as a result of infections originating from the aortic homograft. In patient 24 the aortic homograft caused a lethal miliary tuberculosis, as described by Anyanwu et al. ${ }^{15} \mathrm{Calcifica}-$ tion and obstruction due to compression by sternal tissue was seen in patient 17 , necessitating late graft replacement. In 14 patients with a postoperative follow-up time ranging from 6 months to 9 years 8 months (mean 2 years 7 months) the aortic homograft has not caused any problems.

Persistent cyanosis after the Fontan operation for tricuspid atresia can be caused by intrapulmonary right- to-left shunting if a previously constructed Glenn anastomosis has been left intact, as described above and previously by others. ${ }^{16}{ }^{17}$ These late complications make the Glenn anastomosis for us an obsolete procedure for patients with tricuspid atresia, though it might be life saving after a Fontan operation if the inserted conduit undergoes occlusion as described by Mair et al."1 Occasionally, as in patient 21 , persistent cyanosis can be caused by an unrecognised unroofed coronary sinus, a rare condition described in detail by Quaegebeur et al. ${ }^{18}$

The long-term results in 21 patients with tricuspid atresia after a Fontan operation and the comparison between patients with and without valved conduit with regard to atrial function and postoperative exercise tolerance lead us to the conclusion that a valved conduit is preferable in patients who have tricuspid atresia with ventriculoarterial concordance, as well as in those with ventriculoarterial discordance. The outlet chamber in tricuspid atresia with ventriculoarterial concordance will grow after incorporation in the pulmonary circuit and therefore should not be bypassed as advocated recently. ${ }^{19}$ Rather it should be used to get an optimal physiological result from the Fontan operation in the form of a four-chambered heart with four valves. The disadvantages of using an aortic homograft are few, provided that the graft is fresh and sterilised with antibiotics ${ }^{20}$ and that the antibiotic mixture used is effective against Mycobacterium tuberculosis.

Since the Fontan operation is a physiological and not an anatomical correction careful follow-up studies remain necessary, though happily the vast majority of patients progress as if they had undergone a complete repair.

\section{References}

' Fontan F, Baudet E. Surgical repair of tricuspid atresia. Thorax 1971;26:240-8.

${ }^{2}$ Kreutzer G, Galindez E, Bono H, de Palma C, Laura JP. An operation for the correction of tricuspid atresia. J Thorac Cardiovasc Surg 1973;66:613-21.

${ }^{3}$ Stanford W, Armstrong RG, Cline RE, King TD. Right atrium-pulmonary artery allograft for correction of tricuspid atresia. JThorac Cardiovasc Surg 1973;66:105-11.

${ }^{4}$ Ross DN, Somerville J. Surgical correction of tricuspid atresia. Lancet 1973; ; :845-9.

${ }^{5}$ Henry JN, Devloo RAE, Ritter DG, Mair DD, Davis GD, Danielson GK. Tricuspid atresia. Successful surgical "correction" in two patients using porcine xenograft valves. Mayo Clin Proc 1974;49:803-10.

${ }^{6}$ Tatooles CJ, Ardekani RG, Miller RA, Serrato M. Operative repair for tricuspid atresia. Ann Thorac Surg 1976;21:499503.

${ }^{7}$ Gago O, Salles CA, Stern AM, Spooner E, Brandt RL, Morris JD. A different approach for the total correction of tricuspid atresia. J Thorac Cardiovasc Surg 1976;72:209-14. 
${ }^{8}$ Murray GF, Herrington RT, Delany DJ. Tricuspid atresia. Corrective operation without a bioprosthetic valve. Ann Thorac Surg 1977;23:209-14.

${ }^{9}$ Edwards JE, Burchell HB. Congenital tricuspid atresia: a classification. Med Clin North Am 1949;33:1177-96.

${ }^{10}$ Bowman Jr FO, Malm JR, Hayes CJ, Gersony WM. Physiological approach to surgery for tricuspid atresia. Circulation 1978;58, suppl:83-6.

${ }^{11}$ Mair DD, Fulton RE, Danielson GK. Thrombotic occlusion of Hancock conduit due to severe dehydration after Fontan operation. Mayo Clin Proc 1978;53:397-402.

${ }^{12}$ Doty DB, Marvin WJ, Lauer RM. Modified Fontan procedure. Methods to achieve direct anastomosis of right atrium to pulmonary artery. $J$ Thorac Cardiovasc Surg 1981;81:470-5.

${ }^{13}$ Gale AW, Danielson GK, McGoon DC, Wallace RB, Mair DD. Fontan procedure for tricuspid atresia. Circulation 1980;62:91-6.

${ }^{14}$ Björk VO, Olin CL, Bjarke BB, Thorén CA. Right atrial-right ventricular anastomosis for correction of tricuspid atresia. $J$ Thorac Cardiovasc Surg 1979;77:452-8.
${ }^{15}$ Anyanwu CH, Nassau E, Yacoub M. Miliary tuberculosis following homograft valve replacement. Thorax 1976;31:101-6.

${ }^{16}$ Bargeron Jr LM, Karb RB, Barcia A, Kirklin JW, Hunt D Deverall PB. Late deterioration of patients after superior vena cava to right pulmonary artery anastomosis. $\mathrm{Am} \mathrm{J}$ Cardiol 1972;30:211-6.

${ }^{17}$ Mc Faul RC, Tajik AJ, Mair DD, Danielson GK, Seward JB. Development of pulmonary arteriovenous shunt after superior vena cava - right pulmonary artery (Glenn) anastomosis. Circulation 1977;55:212-6.

${ }^{18}$ Quaegebeur J, Kirklin JW, Pacifico AD, Bargeron Jr JM. Surgical experience with unroofed coronary sinus. Ann Thorac Surg 1979;27:418-25.

${ }^{19}$ Neveux JY, Dreyfus G, Leca FL, Marchand M, Bex JP. Modified technique for correction of tricuspid atresia. JThorac Cardiovasc Surg 1981;82:457-60.

${ }^{20}$ Saravelli OA, Somerville J, Jefferson KE. Calcification of aortic homograft used for reconstruction of the right ventricular outflow tract. J Thorac Cardiovasc Surg 1980;80:90920. 